\title{
3D-visualization and analysis of macro- and meso-porosity of the upper horizons of a sodic, texture-contrast soil
}

\author{
L. Jassogne, A. MCNeill \& D. Chittleborough \\ University of Adelaide, School of Earth and Environmental Sciences, Waite Campus, PMB1, Glen Osmond SA 5064, Australia
}

\begin{abstract}
Summary
The lower E and upper B horizons of sodic, texture-contrast soils are a formidable barrier to most annual and many perennial crops. The research presented here is part of a wider study into the nature of subsoil constraints to root exploration. The aim of this study was to characterize in three dimensions the macroand meso-porosity across the E horizon-Btn horizon interface of a sodic, texture-contrast soil using X-ray computed tomography (CT). Intact soil cores of 50-cm length and $15-\mathrm{cm}$ diameter were scanned with a medical CT X-ray machine. The pore volume reconstructed from these scans had a resolution of $0.3 \times$ $0.3 \times 0.4 \mathrm{~cm}$ (in the $\mathrm{x}, \mathrm{y}, \mathrm{z}$ dimensions, respectively). This resolution allowed visualization and quantification of the macroporosity of the intact cores. Undisturbed samples of $1.5-\mathrm{cm}$ diameter and 4-cm length were carefully excised from the interface and scanned with micro-CT X-ray equipment. The reconstructed pore volumes had an isotropic resolution of $19 \mu \mathrm{m}$ that allowed analysis of the mesoporosity just on the boundary between the E and Btn horizons. Mesoporosity decreased across the interface and increased lower in the Btn horizon. The distribution of the pores at the macro- and meso-scales showed the importance of the smaller pores in the A and E horizons, whereas most of the porosity in the Btn horizon was attributed to the larger pores. Pores in this sodic, texture-contrast soil were not distributed homogeneously at either the macro- or meso-scale. A greater proportion of the pores in the E-B interface were horizontal than in the upper A1, upper E and lower Btn horizons. Some 'coiling' of the pores was also apparent in the interface. The shape of some pores (long tubular pores) suggested formation by roots as they drilled through the soil. The orientation of these pores was a function of physical (and possibly chemical) impedance at the interface.
\end{abstract}

\section{Introduction}

Approximately $60 \%$ of the 20 million hectares of soils used for cropping in Australia are sodic and farming practices on these soils are mainly performed under dryland conditions. More than $80 \%$ of these sodic soils have dense, clay subsoils with high sodicity $(\mathrm{ESP}>6 \%)$ and are strongly alkaline $(\mathrm{pH}>8.5)$ (Rengasamy, 2002). Worldwide there are approximately 135 million hectares of such soils, formerly known as Solonetz or Solodised Solonetz (Stace et al., 1968). In addition to their sodicity, these soils invariably have an abrupt textural change between the A (or E) and B horizons (Chittleborough, 1992). Textures of the A and E horizons are usually sands or loamy sands; B horizons are clays or sandy clays. The clay horizons are very dense (bulk densities $>2 \mathrm{~g} \mathrm{~cm}^{-3}$ are common), and

Correspondence: L. Jassogne. E-mail: laurence.jassogne@adelaide.edu.au Received 28 April 2005; revised version accepted 4 May 2006 present a major physical constraint for both annual and perennial vegetation. Access by root systems to water and nutrients is severely restricted (Clark et al., 2003). In the decades following clearing for agriculture, these soils have been subject to either, or a combination of, waterlogging, dryland salinity, erosion and acidification. In addition to the inherent constraints of sodicity and texture-contrast, agricultural crops must cope with a range of supplementary chemical and structural constraints (Cox et al., 2002; Rengasamy et al., 2003).

Previous studies have shown that few roots tend to grow in the immediate vicinity of the E horizon-B horizon interface of these sodic soils (McNeill et al., 2004). In this paper we will use the term E-B interface to refer to the immediate vicinity of the boundary between the E horizon and the Btn horizon. Previous studies of relationships between soil structure and root distribution in a texture contrast soil, using phase contrast imaging (PCI), observed that roots tended to grow more vertically 
than horizontally in the topsoil and more horizontally than vertically at the interface with the subsoil and at the top of the B horizon (Moran et al., 2000). The branching intensity also decreased with depth. Roots often exploit cracks, voids and large pores, or enlarge smaller pores by displacing soil particles (Clark et al., 2003). Pores provide an easy pathway through the soil matrix because of relatively little mechanical impedance and because they improve contact with oxygen, water and nutrients. Furthermore, the environment around soil macropores has been shown to be chemically and microbiologically different from the bulk soil (Pankhurst et al., 2002). The size of the macropore sheath, i.e. the zone around macropores in which $80 \%$ of the roots are located (Stewart et al., 1999), may be an indication of the level of inhibition for root growth exerted by the soil matrix. A small macropore sheath may indicate that the roots are not evenly distributed throughout the soil matrix, i.e. roots are clumping. One of the implications of this type of root distribution, closely related to macropore distribution, is that nominally available water in the subsoil is poorly accessible by plants. Plants experience water stress even though measurements of soil water content indicate that there is sufficient water in the subsoil to meet demand (Pierret et al., 1999).

These observations demonstrate the importance of quantifying soil structure and the relationship between pores and roots. Many efforts have been made to characterize porosity using twodimensional (2D) image analysis. These include cross-sections from soil reconstructed from tomography (Crestana et al., 1986; Phogat \& Aylmore, 1989; Warner et al., 1989) and soil thin sections (McBratney et al., 1992; Moran \& McBratney, 1992; Vogel, 1997; Li et al., 2004). However, the representation of a three-dimensional (3D) object in a random $2 \mathrm{D}$ cross-section gives only a partial view of reality. 3D-characterization of macropores is the only way to define correctly the continuity of the pores: an important property of pore structure because it largely determines water movement through soil (Vogel, 1997). Tomography has been shown to be a useful tool in this respect (Heijs et al., 1995; Moreau et al., 1999; Perret et al., 1999; Clausnitzer \& Hopmans, 2000). X-ray computed tomography
(CT) is a non-invasive technique that has been used for the characterization of pores and roots in three dimensions in disturbed and undisturbed soils (Heeraman et al., 1997; Pierret et al., 1999; Perret et al., 1999; Pierret et al., 2002; Gregory et al., 2003).

Few 3D studies have been undertaken at the meso-scale on intact soil cores. In this paper, we adopt the pore-size classification of Brewer (1964), in which macroporosity refers to pores $>75 \mu \mathrm{m}$ in size and mesopores $30-75 \mu \mathrm{m}$. Most studies at the meso-scale on undisturbed samples have been invasive and the analysis carried out in pseudo-3D (e.g. Moran et al., 2000). Other 3D studies at the meso-scale were undertaken on disturbed soil samples (Gregory et al., 2003). There is a trade-off between resolution, large field of view and the ability to image in three dimensions. Images of high resolution can only be obtained for small samples with the technology currently available. Using this technology, we report an attempt to visualize and quantify the macro- and mesopore characteristics of a soil in the undisturbed state across the E-B interface that could be of relevance in explaining root growth in those soils. We predict that these characteristics will be major determinants of the pathway of root growth in these soils.

The objective of this study was to characterize porosity at the interface of a soil with strong texture contrast at the macro- and meso-scale. The porosity of the A, E and upper B horizons of a sodic, texture-contrast soil was visualized using computed tomography and the 3D-characteristics of pores that were assumed relevant for root growth were calculated.

\section{Materials and methods}

\section{Field sampling}

Undisturbed soil cores (50-cm depth by $15-\mathrm{cm}$ diameter) were taken with a drill rig from a sodic soil with strong texture-contrast on an experimental site near Wharminda, on the Eyre Peninsula, south Australia $\left(33^{\circ} \mathrm{S}, 136^{\circ} \mathrm{E}\right)$. The soil is a Yellow Sodosol (Isbell, 1996) or Natrixeralf (Soil Survey Staff, 1999). Relevant soil characteristics are summarized in Table 1. The particle size was measured with the hydrometer method. For the porosity

Table 1 General characteristics of an undisturbed soil core $(15 \mathrm{~cm}$ diameter, $50 \mathrm{~cm}$ depth) from Wharminda, South Australia

\begin{tabular}{|c|c|c|c|c|c|c|c|c|c|}
\hline Depth $/ \mathrm{cm}$ & Horizon & Clay $/ \%$ & Silt $/ \%$ & Sand $/ \%$ & $\mathrm{pH}\left(\mathrm{H}_{2} \mathrm{O}\right)$ & $\mathrm{EC}^{\mathrm{a}} / \mathrm{ds} \mathrm{m}^{-1}$ & $\mathrm{CEC}^{\mathrm{b}} / \mathrm{cmol}^{\mathrm{c}} 100 \mathrm{~g}^{-1}$ & $\mathrm{ESP}^{\mathrm{c}} / \%$ & Porosity $/ \%$ \\
\hline $10-15$ & $\mathrm{E}$ & 0 & 2.5 & 97.5 & 8.1 & 0.07 & 4.5 & 4.0 & $38 \pm 2$ \\
\hline $20-25$ & Btn & 15 & 2.5 & 82.5 & 9.1 & 0.13 & 4.5 & 8.0 & $23 \pm 3$ \\
\hline $25-30$ & Btn & 30 & 2.5 & 67.5 & 9.1 & 0.20 & 10.2 & 6.7 & $22 \pm 1$ \\
\hline $30-40$ & Btn & 45 & 2.5 & 52.5 & 9.5 & 0.45 & 20.6 & 20.4 & $44 \pm 8$ \\
\hline
\end{tabular}


calculations, derived from bulk density measurements, we assumed a solid density of $2.65 \mathrm{~g} \mathrm{~cm}^{-3}$. Cores were stored at $4^{\circ} \mathrm{C}$ to avoid modification of the soil structure after sampling.

\section{CT scanning}

At the Queen Elizabeth Hospital in Adelaide, three soil cores were scanned in a medical CT machine (Toshiba Aquilon, Tokyo, Japan) operating at $120 \mathrm{keV}$ and a current of $100 \mathrm{~mA}$. The pixel resolution of the reconstructed images was $0.3 \mathrm{~mm}$. An image of the cross section was taken every $0.4 \mathrm{~mm}$ (z-resolution) but the actual resolution was about twice these values because of volume-averaging effects. Following the coarse CT-scanning, three subsamples ( $4 \mathrm{~cm}$ long and $1.5 \mathrm{~cm}$ diameter) were dissected by a scalpel from the E-B interface of one core, and scanned using a micro-CT machine (Skyscan 1072, Aartselaar, Belgium) operating at $100 \mathrm{keV}$ and $98 \mathrm{~mA}$. Pixel resolution of the scan was $19 \mu \mathrm{m}$ and the distance between two successive CT slices was $19 \mu \mathrm{m}$. The actual resolution of those images was twice the pixel resolution because of volume-averaging effects. Most biopores in soil tend to meander either horizontally or vertically so the distance between subsequent CT slices was taken as small as possible to reveal detail. X-ray computed tomography of the soil provided images, i.e. maps of attenuation coefficients, of the soil that were related to soil density.

\section{Binary thresholding}

The 2D images were segmented with a global-threshold value based on the greyscale histogram to differentiate soil matrix and pores. The threshold value, computed using the maximum entropy threshold algorithm in ImageJ (http://rsb.info.nih. gov/ij/), was selected at the point where the entropy (S) of the grey level histogram was maximized. The entropy, being a measure of the uncertainty of any event, was calculated as:

$$
\mathrm{S}=-\sum\left(P \times \log _{2}(P)\right)
$$

where $P$ was the probability of a pixel greyscale value in the image. When a greyscale image was segmented, the pixels with a value smaller than the threshold value were assigned the value 0 , and were considered as pixels representing the soil matrix. These pixels were called background. The pixels larger than the threshold value were assigned the value 1 , represented pore space and were termed foreground pixels. After segmentation, a median filter, with a neighbourhood of two pixels, was applied to eliminate noise (Perret et al., 1999).

A global threshold based on the greyscale histogram led to misidentification of pixels because of finite resolution effects or noise in real 3D images (Al-Raoush \& Willson, 2005). As a consequence, the connectivity of a number of pores in this experiment was disrupted (Figure 1) and therefore the trends in the data will be commented on rather than the absolute values. In further experiments, segmentation algorithms that apply local

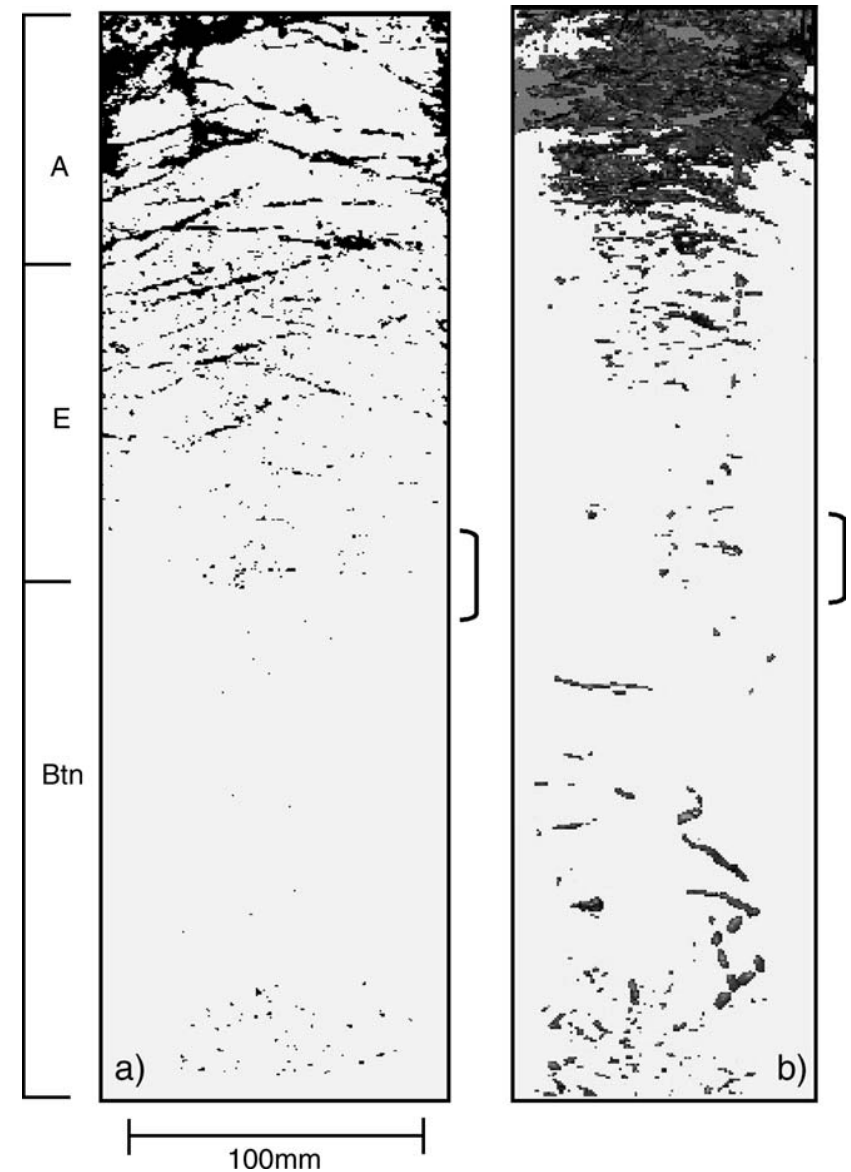

Figure 1 (a) 2D view of the pores $>1 \mathrm{~mm}$ in the upper $40 \mathrm{~cm}$ of a sodic texture-contrast soil and (b) $3 \mathrm{D}$ reconstruction of the macroporosity generated with a medical CT machine. The vertical bars indicate the approximate position of the small samples in Figures 2 and 3.

thresholding techniques will be evaluated (Oh \& Lindquist, 1999; Pierret et al., 2002).

\section{Volumetric porosity and pore size distribution}

The porosity, 3D pore-size distribution, numerical density (i.e. the number of pore networks per volume of soil) and maximum connected volume of the three large intact soil cores and the three subsamples were measured and calculated by loading the binary images in the imaging software Amira 3.1 (Mercury Computer Systems, San Diego, CA, USA). Porosity was defined as the total number of voxels of the pore space, divided by the total number of voxels of the sample. The 3D pore-size distribution was calculated by counting the number of disconnected volumes of pore space and separation of the volumes according to this size (i.e. the number of voxels in the disconnected volume). A voxel was recognized as forming part of the volume if it had adjacent voxels of the same value. A visualization model 
of the volume of the pore space was also reconstructed using this software.

\section{$3 D$ tortuosity and inclination}

The skeleton of the pore space was reconstructed by using an algorithm run in Amira 3.0 (Kolesik et al., 2004). The algorithm was based on the $2 \mathrm{D}$-derivation of the distance map and each pixel belonging to the pore space in the binary image was replaced with a grey value equal to that pixel's distance from the nearest background pixel. The pixels with the largest value were connected from one cross-section to the next crosssection to create a skeleton within which every pore was represented by a line. A segment of a pore or a line was the length between two nodes. The nodes were the pixels on every image that were connected to make the skeleton. The same skeleton algorithm calculated the coordinates of every node in the pore space. Using simple geometric theorems, the inclination and tortuosity of the pores were calculated based on the coordinates of the nodes.

Tortuosity $(\tau)$, a dimensionless factor always $>1$, expresses the degree of complexity of the sinuous pore path (Perret et al., 1999). It was defined as:

$$
\tau=L_{\mathrm{e}} / L
$$

where $L_{e}$ was the effective average path and $L$ the shortest distance measured along the distance of the pore.

The inclination of the pore network was calculated from the vertical. Where the inclination from vertical was $<45^{\circ}$, the pore was considered vertical, inclinations between $45^{\circ}$ and $90^{\circ}$ were considered horizontal.

The macropore architecture in the E-horizon (of sand texture) was very complicated because the resolution of the micro-CT scans revealed porosity that was caused by the packing of the sand particles. McDonald et al. (1990) classified this structure as free grain. Applied to the E horizon, the skeleton algorithm generated artefacts, the most obvious of which were loops starting in some nodes. Therefore, the skeleton was recon- structed only for the transition zone between E and Btn horizons and in the upper portion of the Btn horizon. The efficacy of the skeleton, even with the artefacts, was proven after comparing it with the volume reconstruction.

\section{Results and discussion}

In this study, the total porosity calculated on the basis of the bulk density, was greater than the porosity measured from the CT images because measurements made from the images were resolution dependent. It is important to keep in mind that porosity calculations from bulk density are also sensitive to resolution, which is defined by the diameter of the cores and its relationship with the scale of the structure (Moran \& McBratney, 1992).

The porosity in the undisturbed large soil cores decreased drastically as a function of depth, but slightly increased again deeper in the clay layer (Figure 1). The same trend was found for roots growing in texture-contrast soils (McNeill et al., 2004) and confirms that soil structure and root distribution are closely related in these soils (Moran et al., 2000). The porosity of one of the large cores (Core 1) was more than 50 times greater in the E-horizon than in the interface and three and four times greater in the other two large cores (Cores 2 and 3, respectively). The greater porosity in the interface of Core 3 can be explained by further examination of the images. The CT scans showed relatively more root channels passing through the interface of that core. The numerical density, mean network size and maximum network size (Table 2) showed the same trend. The numerical density was 10 times more in the sand layer than in the clay layer, similar to the variation between samples found by Perret et al. (1999) from CT of undisturbed soil cores. Nevertheless, although they stated that numerical density could not be used as an indication of macroporosity, this parameter could be important for the description of root distribution in soils because pore networks provide pathways for roots. The variability of the same parameters between different samples, together with the visual reconstructions (Figures 2 and 3), illustrates the patchy distribution

Table 2 Porosity, numerical density, mean network size and maximum network size of three undisturbed soil cores calculated from the images obtained from a medical CT

\begin{tabular}{|c|c|c|c|c|c|c|}
\hline Core & Horizon & $\begin{array}{c}\text { Depth } \\
\text { analysed } / \mathrm{cm}\end{array}$ & Porosity /\% & $\begin{array}{c}\text { Numerical density } \\
\text { number of pore } \\
\text { networks } / \mathrm{cm}^{-3}\end{array}$ & $\begin{array}{c}\text { Mean pore } \\
\text { volumetric size } / \mathrm{mm}^{3}\end{array}$ & $\begin{array}{c}\text { Maximum network } \\
\text { size } / \mathrm{cm}^{3} \mathrm{~cm}^{-3}\end{array}$ \\
\hline \multirow{2}{*}{1} & $\mathrm{E} / \mathrm{Btn}$ interface & $16-26$ & 0.68 & 4.2 & 45.6 & 0.05 \\
\hline & Btn & $26-43$ & 0.97 & 3.2 & 84.1 & 0.12 \\
\hline 2 & $\mathrm{~A}$ and $\mathrm{E}$ & $0-21$ & 17.47 & 10.2 & 473.9 & 5.21 \\
\hline \multirow[t]{3}{*}{3} & $\mathrm{~A}$ and $\mathrm{E}$ & $0-20$ & 18.69 & 6.1 & 854 & 4.32 \\
\hline & $\mathrm{E} /$ Btn interface & $20-26$ & 0.29 & 1.7 & 48.2 & 0.69 \\
\hline & Btn & $26-41$ & 4.17 & 8.3 & 140.3 & 0.45 \\
\hline
\end{tabular}




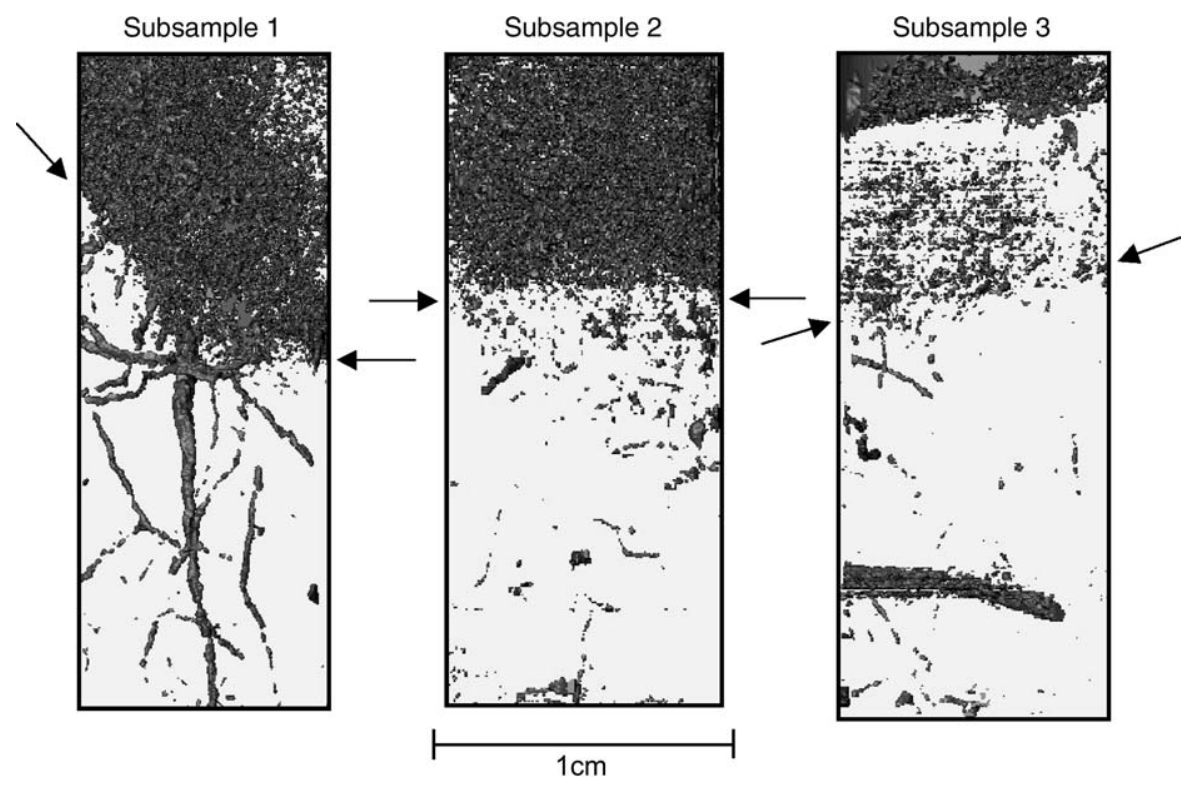

Figure 2 Volume reconstruction of the porosity (pores $>40 \mu \mathrm{m}$ ) of the interface subsamples by means of the micro-CT images. Arrows delineate the E-Btn interface.

of pores in this soil, a feature also reported by Pierret $e t$ al. (1999) and Stewart et al. (1999) for other soil types, and explains the clumped distribution of roots in these horizons.

The volume reconstructions and skeletons of the small intact samples from the interface revealed that the $\mathrm{E}$ and Btn horizons had markedly different porosities (Figures 2 and 3 ) at both the macro-scale and the meso-scale. The macropores $(>75 \mu \mathrm{m})$ visualized with the medical $\mathrm{CT}$ images decreased drastically from the $\mathrm{A}$ and $\mathrm{E}$ horizons to the $\mathrm{E}-\mathrm{Btn}$ interface. The macropores in the $\mathrm{A}$ and $\mathrm{E}$ horizons are formed by layers of dead organic material and old root channels as revealed from destruc- tive analysis of some cores. The macropores in the E-Btn interface and the Btn horizon are mostly tubular in shape and are probably old root channels. As stated above, the meso-porosity of the E horizon, visualized at a spatial resolution of $19 \mu \mathrm{m}$, was largely caused by the packing of the sand particles. Any porosity caused by roots or burrow systems that may have been present could not be visualized in this horizon. Visually, as in the study by Pierret et al. (2002), the pores in the Btn horizon could be separated into two groups. The first group were biopores that were tubular and were suspected to be root channels on the basis of their morphology. This was true for both macropores
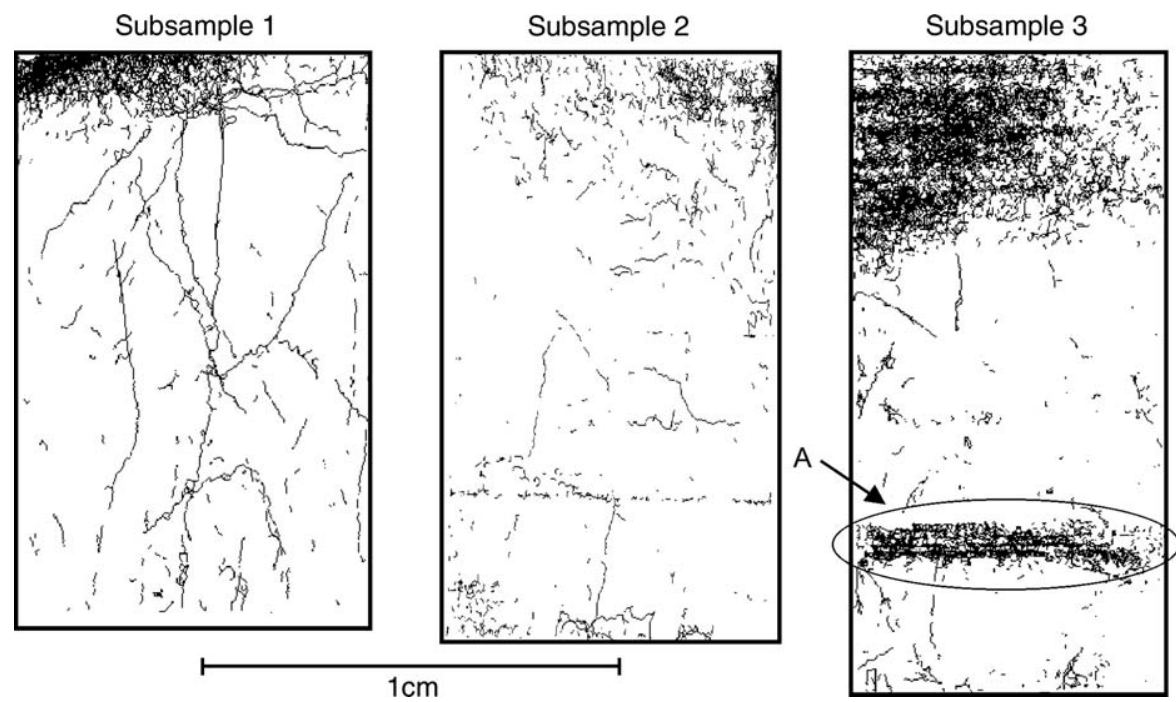

Figure 3 Subsample skeleton reconstruction of the porosity (pores $>40 \mu \mathrm{m}$ ) of samples from the interface samples. Object A in subsample 3 was not taken into consideration for the inclination, tortuosity and length measurements. The skeleton represents pores with a single line (see text). 
and mesopores. It was impossible to make a distinction between live or dead roots by X-ray absorption imaging. The distinction between roots, and pores created by roots, was also not clear. The absorption of those materials was too similar for them to be separated in X-ray absorption images of undisturbed soil samples. The second group contained pores of no particular shape and size. The biopores in this experiment did not have a pronounced vertical or subvertical orientation (Figure 4). This orientation is mostly found in soils that contain earthworms (Pierret et al., 2002) or in soils that do not contain physical barriers to root proliferation. The pore networks in the A and E horizons were well connected, as would be expected in a sandy soil. This is valid at both scales studied. The connectivity of the pores at both scales in the E-Btn interface and the Btn horizon was very small. Increasing the number of pores by root growth would be the only realizable option to increase pore connectivity in those layers.

Structure A in subsample 3 was suspected to be an old root channel containing a young root. The reconstructions suggested a totally different architecture in this biopore compared with the bulk soil. In the field, roots of live crops were observed to follow mostly old root channels. This is consistent with other studies suggesting that roots follow paths of least resistance or paths with different chemical characteristics than the bulk soil (Stewart et al., 1999; Yunusa et al., 2002; Clark et al., 2003).

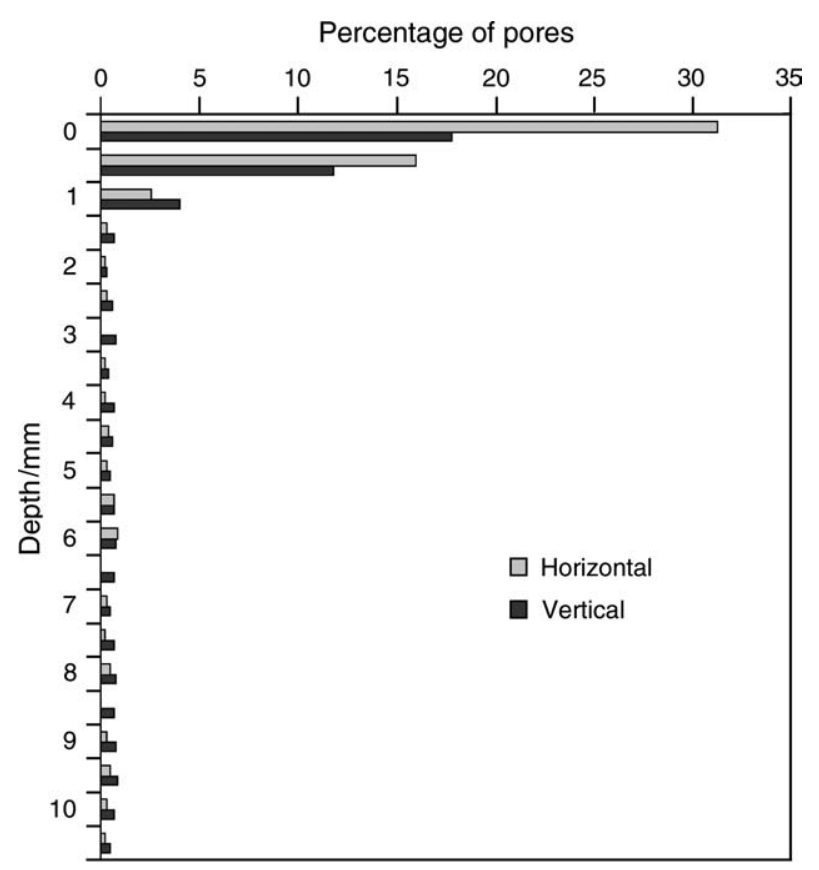

Figure 4 Distribution of horizontal and vertical pores as a function of depth of the interface of subsample 1 obtained by scanning with a micro-CT machine. The $0 \mathrm{~mm}$ depth does not correspond to the top of the undisturbed volume analysed but is the location of the interface of the sample.
In subsamples 1 and 3, pores near the E horizon were more horizontal than vertical, whereas the number of horizontal pores in subsample 2 tended to be greater than the number of vertical pores in the Btn horizon (Figures 4 and 5). Horizontal pores were more tortuous than vertical pores in all three subsamples. These findings confirmed studies in pseudo-three dimensions by phase contrast imaging (PCI) on a similar soil type (Moran et al., 2000). The horizontality of the pores indicated that roots could not easily traverse the interface of this texture-contrast soil. The relatively large tortuosity of the horizontal pores suggested that some roots were searching for paths of least resistance through the Btn-horizon, perhaps cracks caused by wetting and drying or old root channels.

Black decaying roots can be observed down the soil profile in the field to a depth of approximately $2 \mathrm{~m}$ (depth of the pit). The size and shape of the tubular biopores suggest they could not have been formed by annual vegetation. Young roots continuously re-use those old root channels (Creswell \& Kirkegaard, 1995). The measurements of inclination and tortuosity of these biopores in texture-contrast soils indicate that roots that penetrate the subsoils have a role in facilitating root exploration and access to nutrients and water for subsequent species, especially those having root systems limited in penetration ability. The environment of the pores, especially the immediate surface of pores, is very different from the bulk soil (Pierret et al., 1999; Stewart et al., 1999; Pankhurst et al., 2002). This suggests that old root channels are recycled in the following growing season because the environment around these pores is different from the hostile soil matrix.

The volumetric distribution of the small pores declined exponentially across the E-B interface (Figure 6) but the large pores had an irregular distribution. Macro- and microfractures in Vertisols showed the same pattern (Moreau et al., 1999). This pattern was also found in the samples scanned with the microCT showing that this distribution existed at different scales. The pore-size distribution in relation to pore volumes of the

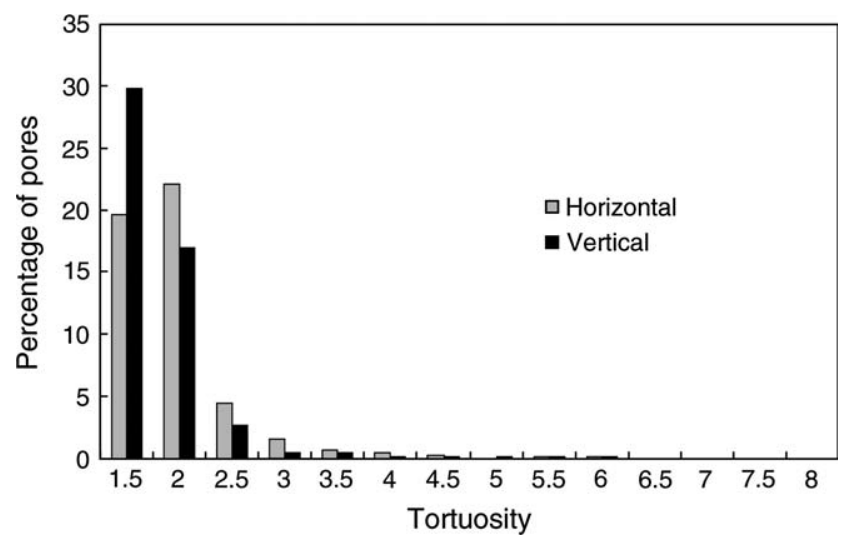

Figure 5 Tortuosity distribution of the 'designated' horizontal and vertical pores in subsample 1 obtained by scanning with a micro-CT machine. This is the same volume analysed in Figure 4. 


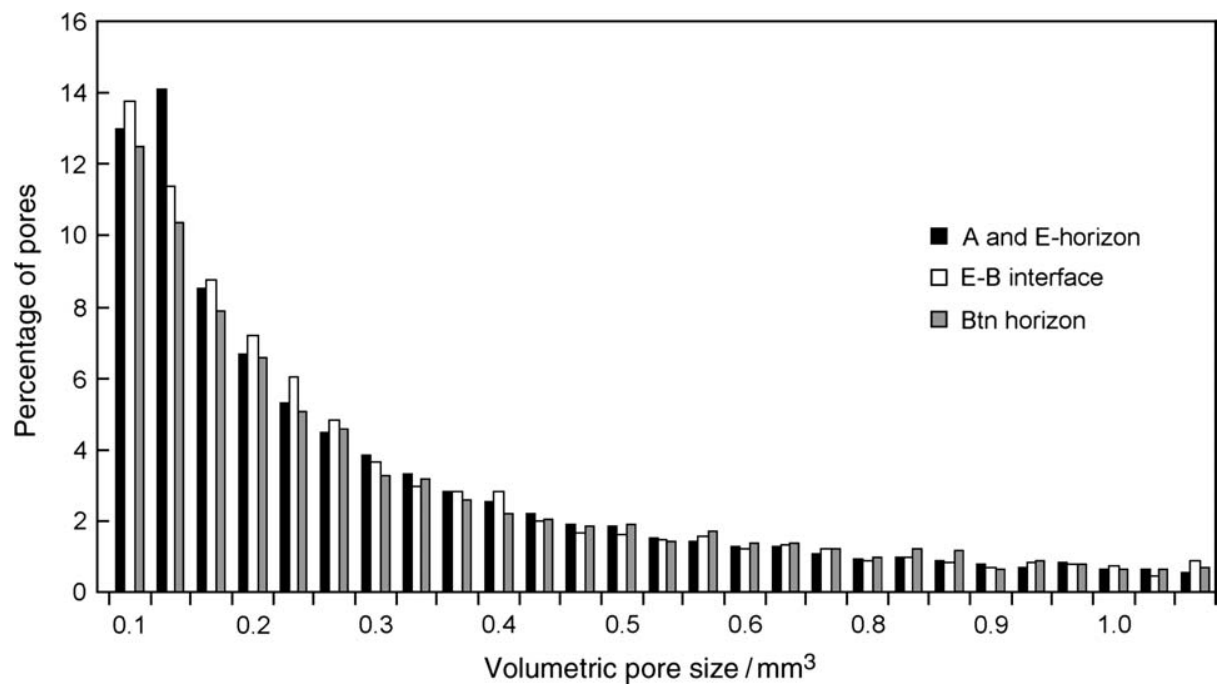

Figure 6 Volumetric pore-size distribution (as a proportion of total number of pores) in the A and E horizons $(0-27 \mathrm{~cm})$, E-B horizon interface $(27-35 \mathrm{~cm})$ and Btn horizon $(35-47 \mathrm{~cm})$ of the undisturbed Core 1 obtained from the medical CT images.

macropores of the A and E horizons showed that most of the porosity was due to the smallest and biggest pores. The distribution of the macropores in the E-Btn interface and the Btn horizon showed that the largest pores were responsible for most of the porosity (Figure 7). Hence, the distribution of the mesopores in the E horizon showed that the smallest pores accounted for most of the porosity. The reason for this could be that the packing porosity of the particles is accounted for in the porosity of the E horizon, whereas the mesopores in the Btn horizon do not represent the packing of particles (Figure 8). The length distribution in all samples did not differ for the horizontal and the vertical pores and did not change as a function of depth (Figure 9).

Assuming that there is no overlap of the two pore types, the mean porosity of the micro-CT images (Table 3 ) could provide an estimate of the mean mesoporosity of the medical-CT images. The three subsamples scanned with the micro-CT were taken in the E-B interface of Core 1. The scans of the undisturbed cores with the medical CT had to be divided into three sections: the sand, the interface and the clay (Table 1). The interface was a mixture of sand and clay because the line between the sand and the clay was not horizontal, but depended on the domes of the Btn horizon. The macroporosity calculated from the medical-CT binary images was $17.6 \%$ in the sand and $0.97 \%$ in the clay. This means that the volumetric proportion of the soil matrix was $82.4 \%$ in the sand and $99.03 \%$ in the clay. The mesoporosity cannot be resolved with the medical-CT images but can be with the micro-CT images. What appeared to be soil matrix in the medical CT-images also contained mesopores resolved with the micro-CT images. So, the soil matrix in Core 1 could be divided into a mesoporosity of $13.1 \%$ in the sand and $0.4 \%$ in the clay. Thus, the E-horizon in Core 1 has a macroporosity of $17.6 \%$ and a mesoporosity of $13.1 \%$, and the total porosity of $30.7 \%$ agrees with the value calculated from the bulk density (Table 1). However, the total porosity in the clay, according to the image analysis, was $1.37 \%$, whereas porosity calculated from the bulk density was $23 \%$. Thus, almost $22 \%$ of the total porosity in the clay horizon was attributed to micropores not resolved by the micro-CT binary images. The smallest pores, i.e. the pores resulting from packing of the sand particles in the E horizon, were resolved with the micro-CT images in accordance with the bulk density measurements.

Table 3 Porosity, numerical density, mean network size and maximum network size of three intact interface subsamples calculated from the images obtained from a micro CT

\begin{tabular}{|c|c|c|c|c|c|c|}
\hline $\begin{array}{l}\text { Interface } \\
\text { subsample }\end{array}$ & Interface & Depth $/ \mathrm{mm}$ & Porosity / \% & $\begin{array}{l}\text { Numerical density } \\
\text { number of pore } \\
\text { networks } / \mathrm{cm}^{-3}\end{array}$ & $\begin{array}{c}\text { Mean pore } \\
\text { volumetric } \\
\text { size } / \mu \mathrm{m}^{3}\end{array}$ & $\begin{array}{c}\text { Maximum network } \\
\text { size } / \mathrm{mm}^{3} \mathrm{~mm}^{-3}\end{array}$ \\
\hline subsample 1 & Btn & $9-18$ & 0.5 & 0.6 & 470.1 & 0.001 \\
\hline \multirow[t]{2}{*}{ subsample 2} & $\mathrm{E}$ & $0-9$ & 12.7 & 53.3 & 350.2 & 0.152 \\
\hline & Btn & $9-19$ & 0.2 & 3.8 & 91.3 & 0.042 \\
\hline
\end{tabular}



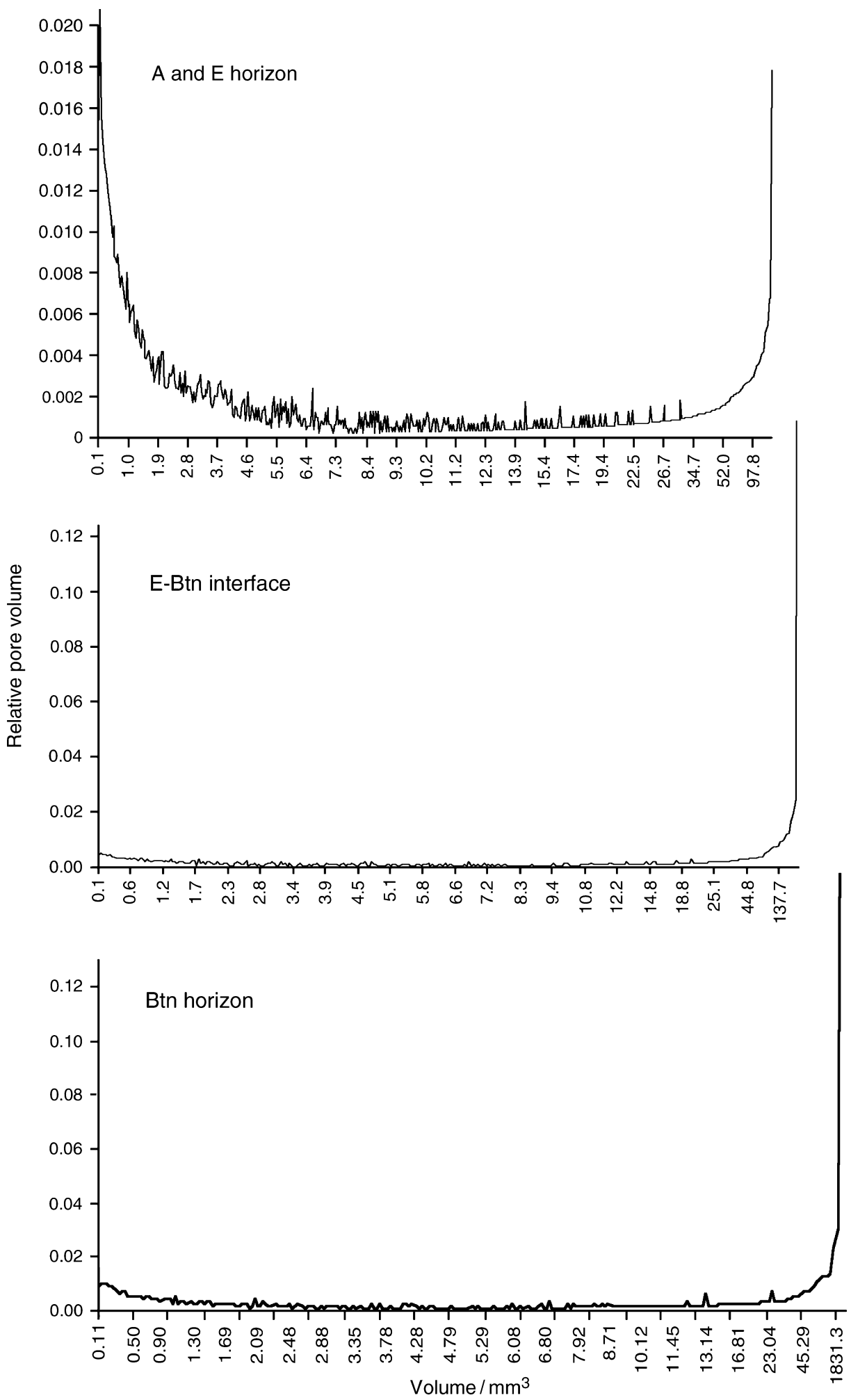

Figure 7 The pore-size distribution in proportions of pore volumes of the macropores in the A, E, interface and Btn horizons derived from the medical-CT images. 

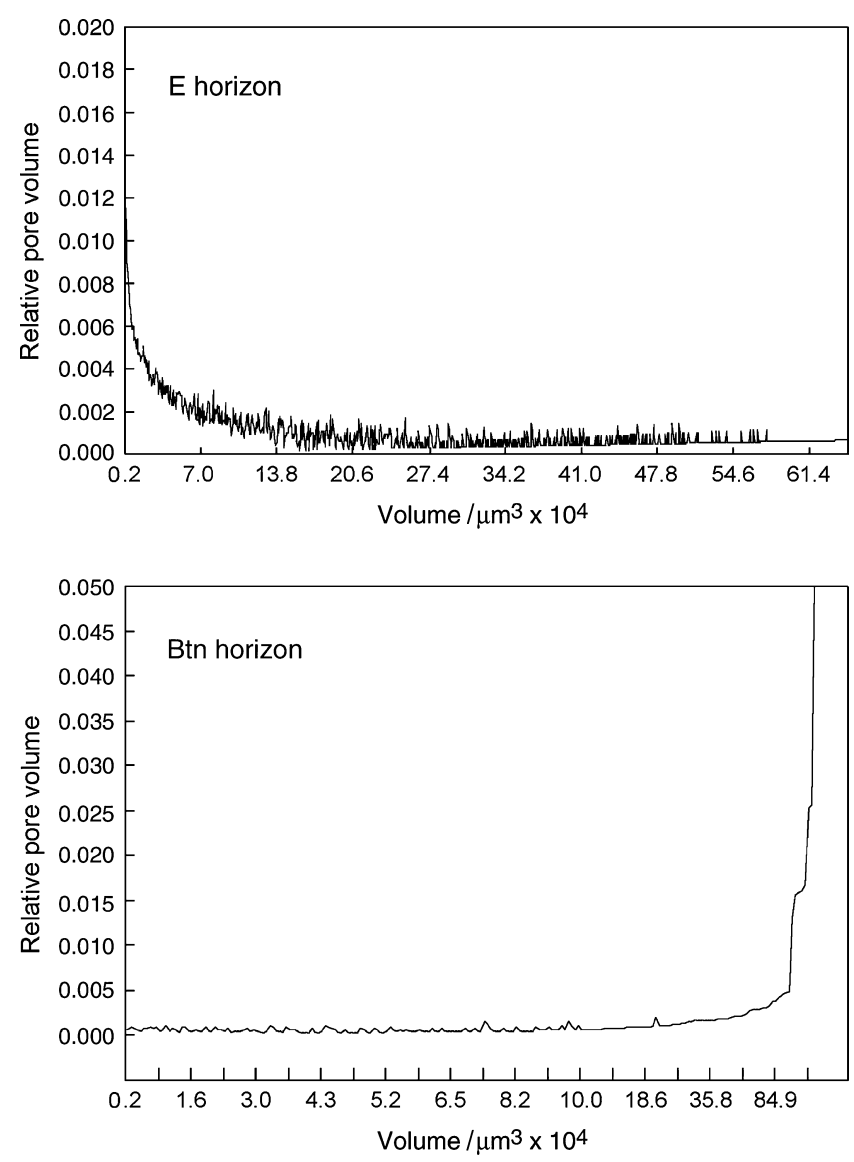

Figure 8 Pore-size distributions in relation to pore volumes of the mesopores of the $\mathrm{E}$ and Btn horizons from the micro-CT images.

Patterns of soil variation are the cumulative result of several physical, chemical and biological processes acting in concert, a process at one scale having feedback to a process at another scale (Bartoli et al., 2005). Variation is to be expected between levels of scale and resolution. This indicates the importance of

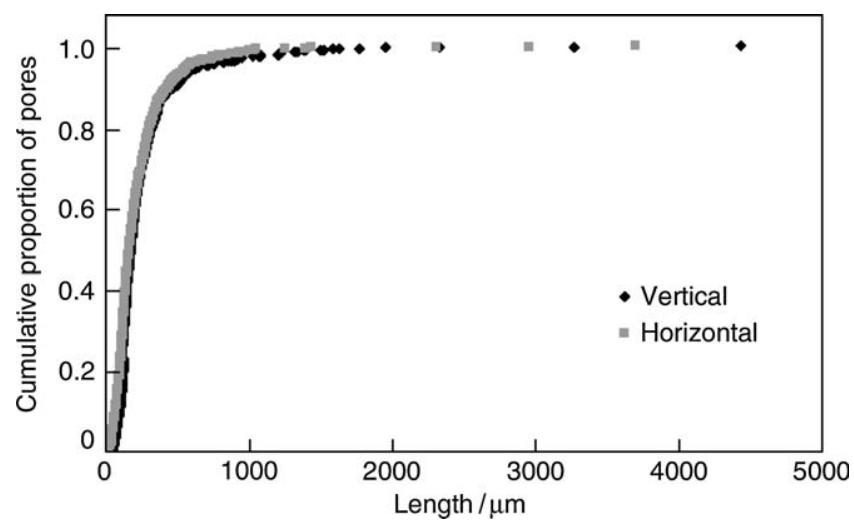

Figure 9 Cumulative length distribution of the horizontal and vertical pores in subsample 1 taken from the interface of an undisturbed core scanned with the micro-CT machine. quantifying porosity at all scales. It can be argued that small samples are not representative, but there is a trade-off between sample size and resolution.

\section{Conclusions}

The distribution of roots in a sodic, texture-contrast soil was related to pore structure. Pores in texture-contrast soils could be separated into two groups. The first consisted of tubular biopores, mainly caused by roots. The second group of pores did not have any particular shape or size. There were more pores in the $\mathrm{A}$ and $\mathrm{B}$ horizons than in the $\mathrm{E}-\mathrm{B}$ interface. The size distribution of pores in all horizons was similar: exponential for small pores and irregular for large pores. This was true at both the mesoand macro-scale. Pores in this texture-contrast soil were not distributed homogeneously. The distribution of macro- and meso-pores was patchy. Pores in the interface and at the top of the B horizon were more horizontal than vertical, and horizontal pores were more tortuous. This behaviour is a function of the impedance of the Btn horizon. Tomography is a useful tool to analyse the architecture of pores at different scales and technological advances in tomography will soon make it possible to quantify pore characteristics at scales finer than those investigated here.

\section{Acknowledgements}

This work would not have been possible without the financial assistance of DEST under the Systemic Infrastructure Initiative and the Cooperative Research Centre for Plant-based Management of Dryland Salinity. We are grateful for the help and advice of Damien Adcock and for laboratory assistance from Colin Rivers. We also thank Peter Kolesik for stimulating discussions and advice.

\section{References}

Al-Raoush, R.I. \& Willson, C.S. 2005. Extraction of physically realistic pore network properties from three-dimensional synchrotron $\mathrm{X}$-ray microtomography images of unconsolidated porous media systems. Journal of Hydrology, 300, 44-64.

Bartoli, F., Genevois-Gomendy, V., Royer, J.J., Niquet, S., Vivier, H. \& Grayson, R. 2005. A multiscale study of silty soil structure. European Journal of Soil Science, 56, 207-224.

Brewer, R. 1964. Fabric and Mineral Analysis of Soils. John Wiley and Sons, New York.

Chittleborough, D. 1992. Formation and pedology of duplex soils. Journal of Experimental Agriculture, 32, 15-25.

Clark, I.J., Whalley, W.R. \& Barraclough, P.B. 2003. How do roots penetrate strong soil? Plant and Soil, 255, 93-104.

Clausnitzer, V. \& Hopmans, J.W. 2000. Pore-scale measurements of solute breakthrough using microfocus X-ray computed tomography. Water Resources Research, 36, 2067-2079.

Cox, J.W., Chittleborough, D.J., Brown, H.J., Pitman, A. \& Varcoe, J.C.R. 2002. Seasonal changes in hydrochemistry along a 
toposequence of texture-contrast soils. Australian Journal of Soil Research, 40, 581-604.

Crestana, S., Cesareo, R. \& Mascarenhas, S. 1986. Using a computedtomography miniscanner in soil science. Soil Science, 142, 56-61.

Creswell, H.P. \& Kirkegaard, J.A. 1995. Subsoil amelioration by plant roots - the process and the evidence. Australian Journal of Soil Research, 33, 221-239.

Gregory, P.J., Hutchison, D.J., Read, D.B., Jenneson, P.M., Gilboy, W.B. \& Morton, E.J. 2003. Non-invasive imaging of roots with high resolution X-ray micro-tomography. Plant and Soil, 255, 351-359.

Heeraman, D.A., Hopmans, J.W. \& Clausnitzer, V. 1997. Three dimensional imaging of plant roots in situ with X-ray computed tomography. Plant and Soil, 189, 167-179.

Heijs, A.W.J., Delange, J., Schoute, J.F.T. \& Bouma, J. 1995. Computed-tomography as a tool for non-destructive analysis of flow patterns in macroporous clay soils. Geoderma, 64, 183-196.

Isbell, R.F. 1996. The Australian Soil Classification. CSIRO, Melbourne.

Kolesik, P., Fouard, C., Prohaska, S. \& McNeill, A. 2004. Automated method for non-destructive $3 \mathrm{D}$ visualisation of plant root architecture using X-ray tomography. In: 4th International Workshop on Functional-Structural Plant Models (eds C. Godin, J. Hanan, W. Kurth, A. Lacointe, A. Takenaka, P. Prusinkiewics, T. DeJong, C. Beveridge \& B. Andrieu), p. 27. UMR CIRAD, CNRS-EPHEINRA-INRIA-IRD-Universite de Montpellier II, Montpellier, France.

Li, D.C., Velde, B. \& Zhang, T.L. 2004. Observations of pores and aggregates during aggregation in some clay-rich agricultural soils as seen in 2D image analysis. Geoderma, 118, 191-207.

McBratney, A.B., Moran, C.J., Stewart, J.B., Cattle, S.R. \& Koppi, A.J. 1992. Modifications to a method of rapid assessment of soil macropore structure by image analysis. Geoderma, 53, 255-274.

McDonald, R.C., Isbell, R.F., Speight, J.G., Walker, J. \& Hopkins, M.S. 1990. Australian Soil and Land Survey Book. Inkata Press, Melbourne.

McNeill, A.M., Kolesik, P., Wauchope, K. \& Coventry, D.C. 2004. Root response to localised nitrogen supply: destructive sampling and non-destructive 3D imaging. In: Abstracts of Poster Papers Presented at the International Rhizosphere Congress, Munich, September 2004. Session 8. Imaging and Spatial Resolution of Diversity and Activities. http://www.gsf.de/iboe/congress/Rhizosphere04_ Abstracts_PP.pdf.

Moran, C.J. \& McBratney, A.B. 1992. Acquisition and analysis of three component digital images of soil pore structure. I. Method. Journal of Soil Science, 43, 541-549.

Moran, C.J., Pierret, A. \& Stevenson, A.W. 2000. X-ray absorption and phase contrast imaging to study the interplay between plant roots and soil structure. Plant and Soil, 223, 101-117.
Moreau, E., Velde, B. \& Terribile, F. 1999. Comparison of 2D and 3D images of fractures in a Vertisol. Geoderma, 92, 55-72.

Oh, W. \& Lindquist, B. 1999. Image thresholding by Indicator Kriging. IEEE Transactions on Patterns Analysis and Machine Intelligence, 21, 590-602.

Pankhurst, C.E., Pierret, A., Hawke, B.G. \& Kirby, J.M. 2002. Microbiological and chemical properties of soil associated with macropores at different depths in a red-duplex soil in NSW Australia. Plant and Soil, 238, 11-20.

Perret, J., Prashner, S.O., Kantzas, A. \& Langford, C. 1999. Threedimensional quantification of macropore networks in undisturbed soil cores. Soil Science Society of America Journal, 63, 1530-1543.

Phogat, V.K. \& Aylmore, L.A.G. 1989. Evaluation of soil structure by using computer assisted tomography. Australian Journal of Soil Research, 27, 313-323.

Pierret, A., Capiowiez, Y., Belzunces, L. \& Moran, C.J. 2002. 3D reconstruction and quantification of macropores using X-ray computed tomography and image analysis. Geoderma, 106, 247-271.

Pierret, A., Moran, C.J. \& Pankhurst, C.E. 1999. Differentiation of soil properties related to the spatial association of wheat roots and soil macropores. Plant and Soil, 211, 51-58.

Rengasamy, P. 2002. Transient salinity and subsoil constraints to dryland farming in Australian sodic soils: an overview. Australian Journal of Experimental Agriculture, 42, 351-361.

Rengasamy, P., Chittleborough, D. \& Helyar, K. 2003. Root-zone constraints and plant-based solutions for dryland salinity. Plant and Soil, 257, 249-260.

Soil Survey Staff 1999. Soil Taxonomy: a Basic System of Soil Classification for Making and Interpreting Soil Surveys. United States Government Printer Office, Government Printer, Washington DC.

Stace, H.C.T., Hubble, C.D., Brewer, R., Northcote, K.H., Sleeman, J.R., Mulcahy, M.J et al. 1968. A Handbook of Australian Soils. Rellim Technical Publications, Glenside, South Australia.

Stewart, J.B., Moran, C.J. \& Wood, J.T. 1999. Macropore sheath: quantification of plant root and soil macropore association. Plant and Soil, 211, 59-67.

Vogel, H.J. 1997. Morphological determination of pore connectivity as a function of pore size using serial sections. European Journal of Soil Science, 48, 365-377.

Warner, G.S., Nieber, J.L., Moore, I.D. \& Geise, A. 1989. Characterising macropores in soil by computed tomography. Soil Science Society of America Journal, 53, 653-660.

Yunusa, I.A.M., Mele, P.M., Rab, M.A., Schefe, C.R. \& Beverly, C.R. 2002. Priming of soil structural and hydrological properties by native woody species, annual crops, and a permanent pasture. Australian Journal of Soil Research, 40, 207-219. 